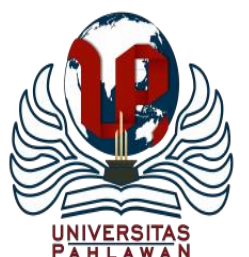

Jurnal Basicedu Volume 5 Nomor 1 Tahun 2021 Halaman 280-287

JURNAL BASICEDU

Research \& Learning in Elementary Education

https://jbasic.org/index.php/basicedu

\title{
Efektivitas Model Pembelajaran Procedural dalam Meningkatkan Keterampilan Vokasional bagi Siswa Tunarungu di Sekolah Luar Biasa
}

\author{
Weweng Paramita Rusadi ${ }^{1}$, Marlina Marlina ${ }^{2}$ \\ Pendidikan Luar Biasa, Fakultas Ilmu pendidikan, Universitas Negeri padang ${ }^{2}$ \\ Email : wewengparamita@ gmail.com ${ }^{1}, \underline{\text { linamuluk@ fip.unp.ac.id }}{ }^{2}$
}

\begin{abstract}
Abstrak
Penelitian ini dilakukan berdasarkan permasalahan yang ditemukan di SLB N 1 Linggo Sari Baganti. Terdapat lima siswa tunarungu yang kurang motivasi dalam pembelajaran keterampilan vokasional, hal ini disebabkan guru belum optimal dalam menggunakan model disaat proses pembelajaran keterampilan vokasional. Tujuan dari penelitian ini adalah untuk membuktikan efektivitas model pembelajaran procedural dalam meningkatkan keterampilan vokasional bagi siswa tunarungu kelas X di SLB I Linggo Sari Baganti. Jenis penelitian ini adalah pre-experimental design atau quasi eksperiment dengan jenis one group pretest and post-test design. Penelitian terdapat dua kali pelaksanaan observasi, yang pertama sebelum eksperimen atau bisa disebut dengan pretest yang dimaksudkan agar memperhatikan kemampuan awal siswa ketika sebelum diberikan tindakan, selanjutnya ada sesuatu eksperimen atau disebut juga dengan post-test ini dimaksudkan agar memperhatikan kemampuan siswa setelah diberikannya tindakan. Desain yang digunakan yaitu one group pretest dan post-test design dalam rancangan ini terdapat satu kelompok tanpa adanya kelompok pembanding. Penelitian ini menggunakan instrumen penelitian dalam instrumen penelitian ini terdapat alat, bahan dan langkah-langkah membuat papan karangan bunga. Tes yang digunakan pada saat sebelum diberikan perlakuan dan setelah diberikan perlakuan dengan menggunakan Wilcoxon dengan SPSS. Hasil penelitian ini adalah bahwa model pembelajaran procedural dapat meningkatkan keterampilan vokasional bagi anak tunarungu di SLBN 1 Linggo Sari Baganti.
\end{abstract}

Kata kunci : keterampilan vokasional, model pembelajaran procedural, siswa tunarungu

\section{Abstract}

This research was conducted based on the problems found in SLB $N 1$ Linggo Sari Baganti. There are five deaf students who lack motivation in learning vocational skills, this is because the teacher has not been optimal in using the model during the learning process of vocational skills. The purpose of this study was to prove the effectiveness of the procedural learning model in improving vocational skills for class X deaf students at SLB I Linggo Sari Baganti. This type of research is pre-experimental design or quasi experiment with the type of one group pretest and post-test design. The study contained two observations, the first before the experiment or what could be called a pretest which was intended to pay attention to the students' initial abilities when before action was given, then there was an experiment or also called a post-test. The design used is one group pretest and post-test design. In this design there is one group without a comparison group. This study uses research instruments in this research instrument, there are tools, materials and steps to make a flower wreath board. The test used at the time before being given treatment and after being given treatment using Wilcoxon with SPSS. The results of this study are that the procedural learning model can improve vocational skills for deaf children at SLBN 1 Linggo Sari Baganti.

Keywords: vocational skills, procedural learning models, deaf students

Copyright (c) 2021 Weweng Paramita Rusadi, Marlina Marlina

$\triangle$ Corresponding author

Address : Jl. Limau Manis, Kec.Pauh, Kota Padang

Email : wewengparamita@gmail.com

Phone : 081268799870

DOI $\quad:$ https://doi.org/10.31004/basicedu.v5i1.654 
281 Efektivitas Model Pembelajaran Procedural dalam Meningkatkan Keterampilan Vokasional bagi Siswa Tunarungu di Sekolah Luar Biasa - Weweng Paramita Rusadi, Marlina Marlina

DOI: https://doi.org/10.31004/basicedu.v5i1.654

\section{PENDAHULUAN}

Keterampilan merupakan kemampuan yang dimiliki dalam melakukan pekerjaan secara maksimal dan terampil dalam segala hal yang bisa membuat hidup menjadi mandiri. Menurut (Sudarto, 2016) keterampilan adalah kemampuan menggunakan ide, akal dan pikiran yang kreatif serta membuat sesuatu yang bermakna sehingga menghasilkan sesuatu yang bernilai dari pekerjaan tersebut. Kecakapan hidup (life skill) didefinisikan sebagai suatu kemampuan yang terdapat pada diri seseorang untuk dapat hidup secara layak dan bermartabat di masyarakat (Zuliansyah \& Hasan, 2018). Oleh sebab itu sangat erat hubungannya dengan psikologi pendidikan ialah bagaimana cara memberikan pelajaran kepada seluruh siswa sehingga siswa senang, saling memperhatikan perbedaan semua siswa menurut prinsip-prinsip psikologi belajar (Marlina, 2014).

Anak tunarungu memiliki gangguan pada indera pendengarannya dari yang bersifat ringan hingga berat yang mengakibatkan kesulitan dalam berkomunikasi baik dengan menggunakan alat bantu dengar tetapi masih tetap memerlukan layanan khusus. (Marlina, 2015). Adanya gangguan yang dialami oleh anak tunarungu maka sangat diperlukannya keterampilan sebagai penunjang kehidupannya untuk memenuhi kebutuhannya hidup ditengah-tengah masyarakat yaitu keterampilan vokasional.

Keterampilan vokasional ialah suatu kecakapan kejuruan yang berhubungan dengan bidang pekerjaan yang terdapat di tengah-tengah masyarakat. Pengembangannya dalam kecakapan hidup disesuaikan dengan minat, bakat, serta kebutuhan yang dimiliki anak tunarungu dan sesuaikan dengan sarana dan prasarana yang ada di sekolah maupun masyarakat (Kosasih, 2012). Keterampilan vokasional memiliki cakupan yang luas, seperti tata boga, tata busana, merangkai, sulam, tata rias, kriya kayu, bercocok tanam, peternakan, dan masih banyak lainnya. Dalam kurikulum pada satuan pendidikan SMALB untuk keterampilan vokasional dikemas dalam kelompok Prakarya dengan alokasi waktu sebanyak 18 jam pelajaran.

Berdasarkan pengamatan ketika melaksanakan studi pendahuluan di SLB Negeri I Linggo Sari Baganti terdapat lima siswa tunarungu yang sedang menempuh pendidikan SMALB yaitu dua orang perempuan dengan inisial VD, FD dan tiga orang laki-laki dengan inisial FZ, AL, WY. Berdasarkan observasi peneliti menemukan di kelas $\mathrm{X}$ bahwa kelima siswa tunarungu tersebut kurang dorongan atau motivasi dalam melaksanakan pembelajaran keterampilan vokasional sehingga pencapaian kelima siswa tunarungu tergolong rendah. Dilihat dari permasalahan tersebut guru kurang mampu menggunakan metode ketika proses pembelajaran sehingga membuat siswa kurang tertarik dan mudah bosan disaat siswa mengikuti pembelajaran keterampilan vokasional. Guru hanya berfokus menggunakan metode ceramah dan demostrasi sehingga hasil yang diperoleh kurang maksimal dan juga kurang mampu memberikan inovasiinovasi baru dalam proses pembelajaran baik dari segi metode maupun dari segi keterampilan yang diberikan. 
282 Efektivitas Model Pembelajaran Procedural dalam Meningkatkan Keterampilan Vokasional bagi Siswa Tunarungu di Sekolah Luar Biasa - Weweng Paramita Rusadi, Marlina Marlina

DOI: https://doi.org/10.31004/basicedu.v5i1.654

Kelemahan dari metode ceramah menurut (Widayati, 2004) adalah mudah terjadi verbalisme, yang visual menjadi rugi, yang auditif lebih besar menerima, membosankan untuk penggunaan yang relatif lama, sulit untuk menyimpulkan bahwa siswa paham dan tertarik dengan apa yang disampaikan, siswa menjadi pasif. Sedangkan kelemahan metode demostrasi menurut (Budiharti, 2010) adalah memerlukan keterampilan khusus, tidak semua siswa terlibat dalam kegiatan demonstrasi, memerlukan kematangan dalam perancangan atau persiapan, keterbatasan dalam sumber belajar, alat pelajaran, situasi yang harus dikondisikan dan waktu untuk mendemonstrasikan sesuatu, tidak dapat dikenakan untuk jumlah siswa yang cukup besar, jika alatnya terlalu kecil penempatan yang kurang tepat menyebabkan demonstrasi tidak dapat dilihat dengan jelas. Melalui dua metode ini pelaksanaan pembelajaran keterampilan vokasional bagi siswa tunarungu di SLBN I Linggo Sari Baganti tidak terlaksana secara efektif dan efisien, apalagi terhadap siswa tunarungu karna lebih mengandalkan visualnya, selain itu dua metode ini membuat siswa kurang aktif dan membosankan serta siswa sering tidak mendapatkan kesempatan secara menyeluruh dalam mendemontrasikan disebabkan waktu yang sedikit.

Berhubungan dengan permasalahan tersebut, peneliti mencoba memberikan model pembelajaran dan jenis keterampilan vokasional di SLB Negeri I Linggo Sari Baganti dengan cara yang berbeda, bentuk berbeda serta dengan menghasilkan nilai jual yang dapat membantu guru maupun siswa itu sendiri. Yaitu dengan menyajikan keterampilan vokasional membuat papan karangan bunga dengan model pembelajaran prosedural yang nantinya diharapkan dapat menarik perhatian siswa untuk belajar keterampilan vokasional.

Penggunaan model pembelajaran prosedural memberikan pemahaman tentang belajar siswa dan mengajarkan ilmu selangkah demi selangkah (Marlina, 2019). Model pembelajaran prosedural diambil kerena dirasa dapat membantu siswa untuk menarik perhatian pada proses pembelajaran dan membuat peserta didik kembali terdorong untuk belajar keterampilan vokasional demi mengembangkan minat dan bakatnya siswa nantinya. Papan karangan bunga diambil karena di samping memiliki nilai jual yang disesuaikan dengan letak sekolah yang berada di tengah-tengah keramaian. Papan karangan bunga di daerah Linggo Sari Baganti sangat dibutuhkan dan untuk jasa pembuatannya sangat jarang ada di daerah tersebut sehingga menjadi peluang besar nantinya setelah siswa tamat sekolah.

Papan karangan bunga ini tergolong ke dalam keterampilan merangkai. Merangkai adalah salah satu keterampilan yang menciptakan suatu keindahan dari benda-benda biasa yang kemudian diubah menjadi suatu kerajinan yang mempunyai nilai keindahan dan nilai ekonimis (Amaliah, 2018). Keterampilan papan karangan bunga adalah simbol untuk mengungkapkan rasa kasih sayang, simpati, turut berduka, turut berbahagia atau ungkapan memberikan semangat (Sari, 2017).

(Reutzel et al., 2014a) model pembelajaran prosedural merupakan model yang dirancang khusus untuk siswa, model ini tidak meninggalkan apapun dan memudahkan siswa dalam membuat 
283 Efektivitas Model Pembelajaran Procedural dalam Meningkatkan Keterampilan Vokasional bagi Siswa Tunarungu di Sekolah Luar Biasa - Weweng Paramita Rusadi, Marlina Marlina

DOI: https://doi.org/10.31004/basicedu.v5i1.654

keterampilan sekaligus mengetahui siswa-siswa yang memerlukan bantuan. Sedangkan menurut (Istarani, 2012) Model pembelajaran prosedural merupakan pembelajaran langsung yang khusus dirancang untuk meningkatkan cara belajar siswa mengenai pengetahuan prosedural dan pengetahuan deklaratif yang bisa dipelajari dengan cara bertahap.

Kelebihan model pembelajaran prosedural, yaitu model pembelajaran yang mampu mengendalikan isi materi, uraian informasi, menekankan poin-poin penting atau kesulitan kesulitan yang mungkin dihadapi siswa. Kesulitan ini menjadi cara yang efektif untuk mengajarkan konsep serta pengetahuan factual dalam membuat keterampilan papan karangan bunga (Anwar \& Lapenia, 2019).

\section{METODE}

Metode penelitian yang digunakan yaitu penelitian pre-experiment dengan jenis one group pretest and post-test (Sugiyono, 2016). Penelitian terdapat dua kali pelaksanaan observasi, yang pertama sebelum eksperimen atau bisa disebut dengan pretest yang dimaksudkan untuk melihat kemampuan awal siswa sebelum diberikan perlakuan, selanjutnya ada sesudah eksperimen atau disebut juga dengan post-test ini dimaksudkan untuk melihat kemampuan siswa setelah diberikannya perlakuan.

Dalam penelitian ini ada dua kali observasi yaitu ketika sebelum diberikan perlakuan atau disebut pretest $\left(\mathrm{O}_{1}\right)$, dan ketika setelah diberi perlakuan disebut post-test $\left(\mathrm{O}_{2}\right)$. Sehingga nanti akan terlihat perbandingan atau perbedaan sebelum diberikan perlakuan dengan setelah diberikan perlakuan. Berikut penjelasan pelaksanaan eksperimen menurut (Yusuf, 2007). Dengan rancangan penelitian seperti terlihat dibawah ini:

\begin{tabular}{|ccc|}
\hline Pretest & Perlakuan & Post-test \\
O1 & $\mathrm{X}$ & $\mathrm{O} 2$ \\
& & \\
\hline
\end{tabular}

Bagan I. Desain Kelompok Tunggal

Keterangan dibawah ini :

O1 : Pretest, melihat kondisi awal siswa sebelum diberi perlakuan dalam membuat keterampilan vokasional papan karangan bunga

$\mathrm{X}$ : Perlakuan dengan menggunakan model pembelajaran procedural

O2 : Post-test, melihat hasil pemahaman siswa dalam membuat keterampilan vokasional papan karangan bunga melalui model pembelajaran procedural

Penelitian ini mengambil subjek di SLBN 1 Linggo Sari Baganti. Subjek pada penelitian ini terdiri dari lima orang siswa tunarungu yang duduk di kelas X satuan pendidikan SMALB di SLBN 1 Linggo Sari Baganti.

\section{Tabel 1. Subjek Penelitian}

\begin{tabular}{ccccc} 
No & $\begin{array}{c}\text { Kode } \\
\text { Nama }\end{array}$ & Umur & Tunarungu & $\begin{array}{c}\text { Jenis } \\
\text { Kelamin }\end{array}$ \\
\hline 1 & VD & 14 th & Ringan & P \\
\hline 2 & FZ & 16 th & Ringan & L \\
\hline 3 & AL & 18 th & Ringan & L \\
\hline 4 & FD & 17 th & Ringan & P \\
\hline 5 & WY & 15 th & Ringan & L \\
\hline Jumlah & & & 5 Orang
\end{tabular}

Teknik pengumpulan data yang digunakan dalam penelitian ini berupa tes. Tes adalah urutan 
284 Efektivitas Model Pembelajaran Procedural dalam Meningkatkan Keterampilan Vokasional bagi Siswa Tunarungu di Sekolah Luar Biasa - Weweng Paramita Rusadi, Marlina Marlina

DOI: https://doi.org/10.31004/basicedu.v5i1.654

pertanyaan, latihan serta alat lain yang dapat digunakan untuk mengukur pengetahuan, keterampilan, kemampuan atau bakat yang dimiliki oleh individu atau kelompok (Arikunto, 2014:193). Alat pengumpulan data yaitu instrumen penelitian. Instrumen pengumpulan data merupakan alat bantu yang digunakan peneliti dalam kegiatan penelitian agar mempermudah peneliti dalam pelaksanaannya (Arikunto, 2005:101).

Untuk data yang tidak berdistribusi normal perhitungannya menggunakan uji non-parametrik yaitu uji wilcoxon sign rank test. Menggunakan taraf signifikansi sebesar $5 \%$ dan dilakukan menggunakan bantuan aplikasi SPSS 23

\section{HASIL DAN PEMBAHASAN}

\section{Nilai Pretest dan Post-test}

Data ini merupakan hasil dari tes model pembelajaran procedural membuat papan karangan bunga sebelum perlakuan dan sesudah perlakuan yang dilakukan oleh subjek penelitian selama pengambilan data berlangsung. Hasil pengumpulan data dalam model pembelajaran procedural adalah sebagai berikut:

\section{Tabel 2. Nilai Pretest dan Post-test}

\begin{tabular}{|c|c|c|c|}
\hline No & Subjek & Pretest & Post-test \\
\hline 1. & VD & 45 & 94 \\
\hline 2. & FZ & 41 & 90 \\
\hline 3. & AL & 40 & 87 \\
\hline 4 & FD & 36 & 86 \\
\hline 5. & WY & 34 & 84 \\
\hline \multicolumn{2}{|c|}{ Jumlah } & 196 & 441 \\
\hline
\end{tabular}

Dari tabel dan grafik, bisa didapatkan hasil persentase pretest dan hasil persentase post-test dengan rumus sebagai berikut :

$$
\begin{aligned}
& \frac{\text { skor perolehan }}{\text { skor maksimal }} \times 100 \%= \\
& \text { Pretest }=\frac{196}{560} \times 100 \%=35 \% \\
& \text { Post-test }=\frac{441}{560} \times 100 \%=78,75 \%
\end{aligned}
$$

Berdasarkan tabel dan grafik, dapat dijelaskan bahwa kemampuan awal (pretest) dan kemampuan setelah diberi perlakuan atau kemampuan akhir (post-test) dapat dilihat keterampilan membuat papan karangan bunga mengalami peningkatan.

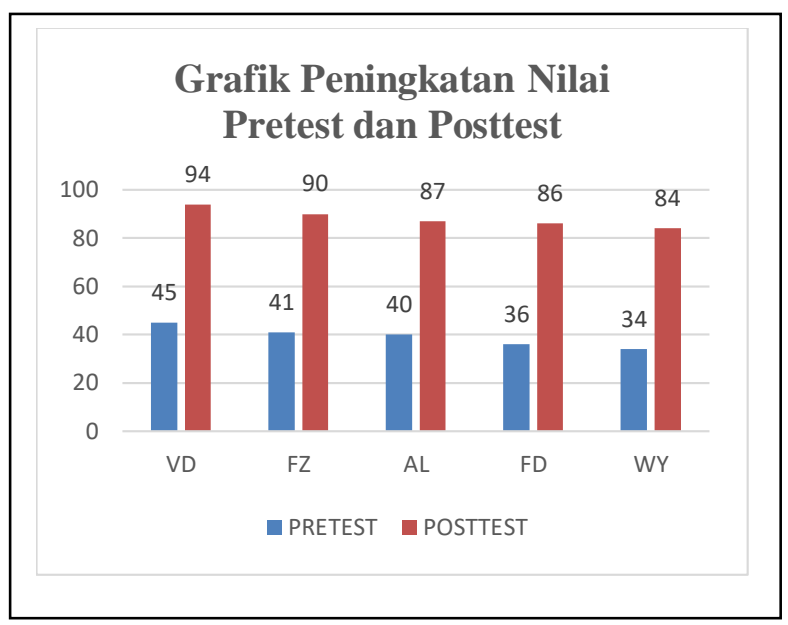

\section{Grafik 1. Peningkatan Hasil Pretest dan Post-test}

Hasil pretest dan post-test dapat dilihat pada table dibawah ini :

Tabel 3. Hasil Pretest dan Post-test

\begin{tabular}{ccccccc}
\hline \multicolumn{5}{c}{ N Minimum Maximum } & SUM Mean & $\begin{array}{c}\text { Std. } \\
\text { Deviation }\end{array}$ \\
\hline Pretest & 5 & 34 & 45 & 196 & 39,20 & 4,324 \\
\hline Posttest & 5 & 84 & 94 & 441 & 88,20 & 3,899 \\
\hline
\end{tabular}

Dari tabel diketahui bahwa nilai tertinggi dari pretest adalah 45 dan nilai terendah adalah 34 . Sedangkan nilai rata-rata dari pretest adalah 39,20. 
285 Efektivitas Model Pembelajaran Procedural dalam Meningkatkan Keterampilan Vokasional bagi Siswa Tunarungu di Sekolah Luar Biasa - Weweng Paramita Rusadi, Marlina Marlina

DOI: https://doi.org/10.31004/basicedu.v5i1.654

Serta nilai tertinggi post-test adalah 94 dan nilai terendahnya 84 , nilai rata-rata posttest 88,20 .

\section{Pengolahan Data}

Setelah mendapatkan nilai pretest dan posttest selanjutnya menentukan nilai rank atau peringkat dari nilai subjek penelitian yang belum dilakukan penelitian (X1) dan setelah diberikan penelitian (X2) dan selanjutnya dianalisis menggunakan uji wilcoxon sign rank test.

Dalam pengujian hipotesis, dibutuhkan syarat dalam analisis data yang dihasilkan dengan membandingkan Asym $p$ Sig. (2 tailed) dengan taraf signifikan $(\alpha)$. Taraf signifikansi yang digunakan dalam analisis yaitu 0.05 atau 5\%, dapat dilihat pada tabel dibawah ini :

Tabel 4. Syarat Pengujian Hipotesis

\begin{tabular}{|c|c|c|c|}
\hline Hipotesis & $\begin{array}{l}\text { Asymp } \\
\text {. Sig. } \\
(2- \\
\text { tailed })\end{array}$ & $\begin{array}{c}\text { Taraf } \\
\text { signifikansi } \\
(\alpha)\end{array}$ & Simpulan \\
\hline $\begin{array}{l}\text { Ho : } \\
\text { Model } \\
\text { pembelajaran } \\
\text { procedural tidak } \\
\text { efektif digunakan } \\
\text { untuk } \\
\text { meningkatkan } \\
\text { keterampilan } \\
\text { vokasional } \\
\text { membuat papan } \\
\text { karangan bunga }\end{array}$ & $>0.05$ & 0.05 & ditolak \\
\hline $\begin{array}{l}\text { Ha : } \\
\text { Model } \\
\text { pembelajaran } \\
\text { procedural } \\
\text { efektif digunakan } \\
\text { untuk } \\
\text { meningkatkan } \\
\text { keterampilan } \\
\text { vokasional } \\
\text { membuat papan } \\
\text { karangan bunga }\end{array}$ & $<0.05$ & 0.05 & diterima \\
\hline
\end{tabular}

Untuk membuktikan hipotesis bahwa model pembelajaran procedural dapat meningkatkan keterampilan vokasional membuat papan karangan bunga, maka digunakan uji analisis wilcoxon sing rank test. Hasil perhitungan analisis adalah sebagai berikut :

Tabel 5. Ranks

\begin{tabular}{|l|l|c|c|c|}
\hline & & N & $\begin{array}{c}\text { Mean } \\
\text { Rank }\end{array}$ & $\begin{array}{c}\text { Sum of } \\
\text { Ranks }\end{array}$ \\
\hline $\begin{array}{l}\text { Post- } \\
\text { test } \\
\text { Pre } \\
\text { test }\end{array}$ & $\begin{array}{l}\text { Negative } \\
\text { Ranks }\end{array}$ & $0^{\mathrm{a}}$ & .00 & .00 \\
\cline { 2 - 5 } & $\begin{array}{l}\text { Positive } \\
\text { Ranks }\end{array}$ & $5^{\mathrm{b}}$ & 3.00 & 15.00 \\
\cline { 2 - 5 } & Ties & $0^{\mathrm{c}}$ & & \\
\cline { 2 - 5 } & Total & 5 & & \\
\hline
\end{tabular}

a. Post-test $<$ Pretest

b. Post-test $>$ Pretest

c. Post-test $=$ Pretest

Tabel 6. Test Statistics ${ }^{a}$

\begin{tabular}{|l|c|}
\hline & Post-test - Pretest \\
\hline$Z$ & $-2,041^{\mathrm{b}}$ \\
\hline Asymp. Sig. (2-tailed) & 0,041 \\
\hline
\end{tabular}

a. Wilcoxon Signed Ranks Test.

b. Based on negative ranks.

\section{Pembahasan}

Berdasarkan hasil perbandingan hasil antara pretest dengan hasil post-test terlihat bahwa adanya peningkatan nilai rata-rata dari kelima siswa tersebut. Dengan kata lain siswa sudah mampu memiliki kemampuan dalam keterampilan vokasional membuat papan karangan bunga setelah diberikan perlakuan berupa model pembelajaran procedural. Dan juga adanya keterampilan vokasional yang baru serta dengan menggunakan model yang menarik yaitu model 
286 Efektivitas Model Pembelajaran Procedural dalam Meningkatkan Keterampilan Vokasional bagi Siswa Tunarungu di Sekolah Luar Biasa - Weweng Paramita Rusadi, Marlina Marlina

DOI: https://doi.org/10.31004/basicedu.v5i1.654

pembelajaran procedural yang terbukti dengan pencapaian hasil yang didapatkan oleh siswa.

Pada penelitian ini sebelum diberikan pretest peneliti memberikan dulu penjelasan mengenai langkah-langkah model pembelajaran procedural membuat papan karangan bunga kemudian pre-test dilakukan dua kali (lembar dokumentasi) untuk melihat kemampuan awal dalam membuat papan karangan. Selanjutnya diberikan perlakuan atau treatment dengan menggunakan model pembelajaran procedural membuat papan karangan bunga diberikan kepada anak sebanyak lima kali pertemuan (lembar dokumentasi), untuk tahap ini tidak dilakukan penilaian. Pada tahap ketiga yaitu post-test (lembar dokumentasi) yang merupakan kemampuan akhir siswa dalam membuat papan karangan bunga.

Penelitian dilakukan peneliti bertujuan membuktikan apakah model pembelajaran procedural efektif atau tidak untuk meningkatkan keterampilan vokasional membuat papan karangan bunga bagi siswa tunarungu terlihat meningkat,, hal ini dilakukan dengan cara membandingkan antara nilai pretest dan post-test dan dibuktikan melalui uji Wilcoxon dengan aplikasi SPSS 23. Dalam artian bahwa model pembelajaran procedural dapat meningkatkan keterampilan vokasional siswa tunarungu.

Penelitian ini releven dengan penelitian (Putri, 2017) yang menyatakan bahwa kemampuan dikte anak tunagrahita ringan meningkat setelah diberikan model pembelajaran procedural. Menurut penelitian (Reutzel et al., 2014b) menyatakan bahwa model pembelajaran procedural dapat membantu siswa dalam membaca inti. Dari semua penelitian tersebut relevan dengan penelitian yang telah dilakukan oleh peneliti dalam hal ini menyatakan hasil yang sama, dengan kata lain penelitian kali ini menunjukkan efektif dalam bidang keterampilan vokasional. Dan dengan penggunaan model pembelajaran procedural juga terbukti bahwa anak tunarungu lebih tertarik dalam proses pembelajaran, sehingga model tersebut dapat membantu guru dalam poses pembelajaran.

\section{SIMPULAN}

Berdasarkan uraian pada pembahasan bahwa model pembelajaran procedural efektif digunakan untuk meningkatkan keterampilan vokasional membuat papan karangan bunga bagi anak tunarungu ringan di SLB N I Linggo Sari Baganti. Hal ini terbukti dari hitungan data yang diperoleh dengan menggunakan rumus uji Wilcoxon dengan SPSS 23.

\section{DAFTAR PUSTAKA}

Amaliah, A. (2018). Upaya Meningkatkan Prestasi Belajar Siswa Pada Matapelajaran Seni Budaya dan Keterampilan Pada Materi Seni Merangkai Bunga Menggunakan Metode Demontrasi (PTK di Kelas $V$ SDN Pagedongan Kec. Baros Kab. Serang). Universitas Islam Negeri" Sultan Maulana Hasanuddin" Banten.

Anwar, A. S., \& Lapenia, P. (2019). Penerapan Model Pembelajaran Explicit Instruction untuk Meningkatkan Hasil Belajar Siswa Pokok Bahasan Cahaya dan Sifatnya pada Siswa Kelas V di SD Negeri 1 Sembawa.

Arikunto, S. (2005). Manajemen Penelitian. Rineka Cipta.

Arikunto, S. (2014). Prosedur Penelitian Suatu Pendekatan Praktik. Rineka Cipta. 
287 Efektivitas Model Pembelajaran Procedural dalam Meningkatkan Keterampilan Vokasional bagi Siswa Tunarungu di Sekolah Luar Biasa - Weweng Paramita Rusadi, Marlina Marlina

DOI: https://doi.org/10.31004/basicedu.v5i1.654

Budiharti, R. (2010). Pembelajaran Fisika Dengan Pendekatan CTL (Contextual Teaching and Learning) Melalui Metode Demonstrasi. Proceeding Biology Education Conference: Biology, Science, Enviromental, and Learning, 7(1).

Istarani. (2012). 58 Model Pembelajaran Inovatif. Media Persada.

Kosasih, E. (2012). Cara Bijak Memahami Anak Berkebutuhan Khusus. Yrama Widya.

Marlina. (2015). Asesmen Anak Berkebutuhan Khusus ( Pendekatan Psikoedukasioanal) (H. Yenni (ed.)). UNP Press.

Marlina, M. (2014). Keterampilan Sosial Anak Berkesulitan Belajar di Sekolah Dasar Inklusif. Penelitian Pendidikan, 5(1).

Marlina, M. (2019). Panduan Pelaksanaan Model Pembelajaran Berdiferensiasi di Sekolah Inklusif. Universitas Negeri Padang.

Putri, R. (2017). Meningkatkan Kemampuan Dikte Melalui Metode Eksplisit Instructions bagi Anak Tunagrahita Ringan Kelas VI di SLB Wacana Asih Padang. Universitas Negeri Padang.

Reutzel, D. R., Child, A., Jones, C. D., \& Clark, S. K. (2014a). Explicit Instruction In Core.

Reutzel, D. R., Child, A., Jones, C. D., \& Clark, S. K. (2014b). Explicit Instruction In Core Reading Programs. The Elementary School Journal, 114(3), 406-430.

Sari, D. E. (2017). Analisis Faktor-Faktor Yang Mempengaruhi Keuntungan Pedagang Karangan Bunga di Kota Bandung. Perpustakaan Fakultas Ekonomi dan Bisnis Unpas Bandung.

Sudarto. (2016). Keterampilan dan Nilai sebagai Materi Pendidikan dalam Perspektif Islam. $A l$ Lubab, 1(1), 105-120.

Sugiyono. (2016). Metode Penelitian Pendidikan: Pendekatan Kuantitatif, Kualitatif, dan R\&D. Alfabeta.

Widayati, A. (2004). Metode mengajar sebagai strategi dalam mencapai tujuan belajar mengajar. Jurnal Pendidikan Akuntansi Indonesia, 3(1).

Yusuf, M. (2007). Metodologi Penelitian. UNP
Press.

Zuliansyah, M., \& Hasan, Y. (2018). Pelaksanaan Program Layanan Keterampilan Vokasional Pangkas Rambut Bagi Siswa SMALB Tunarungu di SLB Negeri 2 Tanjungpinang. 6. 